\title{
Mastitisli Sığırlardan İzole Edilen Staphylococcus aureus İzolatlarının Virülens Gen Profillerinin Belirlenmesi
}

\author{
Ayşe Rümeysa NALÇA ${ }^{1, a}$, Timur GÜLHAN ${ }^{1, b, *}$ \\ ${ }^{1}$ Ondokuz Mayıs Üniversitesi Veteriner Fakültesi Mikrobiyolojisi Anabilim Dalı, SAMSUN \\ aORCID: 0000-0002-3947-6511, bORCID:0000-0003-4798-1427
}

Geliș Tarihi: 03.08.2021

Kabul Tarihi: 12.10.2021

\begin{abstract}
Özet: Bu çalışmada anabilim dalı kültür koleksiyonunda bulunan subklinik mastitisli sığır sütlerinden izole edilen 140 adet stafilokok izolatından Staphylococcus aureus izolatlarının moleküler identifikasyonu ve bazı önemli virülens genlerinin tespiti amaçlandı. Bu amaçla 140 stafilokok izolatı termonükleaz (nuc) gen varlığı yönünden PZR ile incelendi. nuc geni (279 bp) tespit edilen 42 izolat $S$. aureus olarak identifiye edildi. Ayrıca izolatlarda lökotoksin geni (pvl), stafilokokal klasik enterotoksin genleri (sea, seb, sec), eksfolyatif toksin genleri (eta, etb), hemolizin genleri ( $h / a, h / b)$, adezin faktör genleri $(f n b A, f n b B, c l f a)$ ve toksik şok sendrom toksin geni (tst) olmak üzere 12 farklı virülens geninin varlığı 3 farklı multipleks PZR kullanılarak araştıııldı. İolatların 30 (\%71.4)'u clfa, 24 (\%57.1)'ü hla, 14 (\%33.3)'ü hlb, 10 (\%23.8)'u fnbB, 6 (\%14.2)'sıfnbA, 6 (\%14.2)'sıetb, 5 (\%11.9)'i sec, 5 (\%11.9)'i tst, 3 (\%7.1)'ü sea, 2 (\%4.7)'si pvl ve 1 (\%2.3)'i eta geni açısından pozitif bulundu. İzolatların hiçbirinde seb geni saptanamadı. İzolatların38'inde bir ya da daha fazla virülens geni, $29^{\prime}$ unda ise iki ya da daha fazla virülens geni belirlendi. 4 izolatta ise incelenen virülens genlerin hiçbiri saptanamadı. İncelenen izolatlarda en fazla tespit edilen virülens genlerin clfa ve hla olduğu görüldü. Sonuç olarak sınırlı dahi olsa sığır mastitislerinin patogenezinde rol oynayan virülens gen patternleri ortaya konuldu. Çalışma sonuçlarının sığır mastitislerinin etiyolojisinde önemli rol oynayan S. aureus'a ait virülens faktörlerinin karakterizasyon çalışmalarına katkı sağlayacağı kanaatine varıldı.
\end{abstract}

Anahtar Kelimeler: Mastitis, Sığır, S. aureus, Virülens gen profili.

\section{Determination of Virulence Gene Profiles of Staphylococcus aureus Isolated from Cattle with Mastitis}

\begin{abstract}
This study aimed to determine the molecular identification of Staphylococcus aureus isolates and some important virulence genes from 140 staphylococci samples isolated from cow milk with mastitis in the culture collection of the department. For this purpose, the presence of the thermonuclease (nuc) gene in $140 \mathrm{~S}$. aureus isolates was examined by PCR. Forty-two isolates that were positive for the nuc gene (279 bp) were identified as S. aureus. In addition, the isolates were examined for the presence of 12 different virulence genes, including leukotoxin gene ( $p v /)$, staphylococcal classical enterotoxin genes (sea, seb, sec), exfoliative toxin genes (eta, etb), hemolysin genes ( $h l a, h l b)$, adhesin factor genes ( $f n b A$, $f n b B, c l f a)$, and toxic shock syndrome toxin gene (tst), using three different multiplex PCR. Of the isolates were found to be positive 30 (71.4\%) for clfa, 24 (57.1\%) hla, 14 (33.3\%) hlb, 10 (23.8\%) fnbB, 6 (14.2\%) fnbA, 6 (14.2\%) etb, 5 (11.9\%) sec, 5 (11.9\%) tst, 3 (7.1\%) sea, $2(4.7 \%) \mathrm{pvl}$, and $1(2.3 \%)$ eta genes. The seb gene was not detected in any of the isolates. At the same time one or more virulence genes were determined in 38 of 42 isolates, two or more virulence genes in 29 of the isolates. None of the virulence genes examined in 4 isolates could be detected. It was seen that the mostdetected virulence genes in the analyzed isolates were clfa and hla. As a result, virulence gene patterns that play a role in the pathogenesis of bovine mastitis, even if limited, were revealed. It was concluded that the results would contribute to the characterization studies of virulence factors belonging to $S$. aureus, which play an important role in the etiology of bovine mastitis.
\end{abstract}

Keywords: Bovine, Mastitis, S. aureus, Virulence gene profile.

\section{Giriş}

Mastitis, meme dokusunun ve meme bezinin bakteriyel, viral, fungal ve paraziter etkenler nedeniyle yangılanmasıdır. Enfeksiyon genellikle hijyenik ve yönetimsel uygulamaların yokluğunda, sağım sırasında enfekte ineklerden enfekte olmayan ineklere yayılabilmektedir (Kotzamanidis ve ark., 2021).

Sığır mastitislerinden en sık izole edilen etkenlerin başında Staphylococcus (S.) aureus gelmektedir. Etken hem insanların hem de hayvanların derisinde, burnunda ve solunum yollarında bulunan kommensal mikrobiyotanın bir parçasını oluşturmaktadır. S. aureus, yüzeysel deri ve yumuşak doku enfeksiyonlarından yaşamı tehdit eden septisemiye kadar, birçok ciddi hastalık oluşturan bir patojendir. Diğer yandan süt endüstrisi için oldukça maliyetli klinik ve subklinik sığır mastitisinin en yaygın etiyolojik ajanıdır (Ren ve ark., 2020). 
S. aureus, adezinler, kapsüler bir polisakkarit ve ekzoenzimler gibi çok sayıda virülens faktörü üretme kapasitesine sahiptir. Etken aynı zamanda hemolizinler, koagülaz, slime ve protein A gibi meme bezine kolonize olma kabiliyetine katkıda bulunan ekzoproteinler de üretebilmektedir. $\alpha$ ve $\beta$ hemolizinler, mastitisin patogenezinde önemli virülens faktörlerdir. $S$. aureus izolatlarının patojenitesi; adherens özellikleri, çeşitli toksinler, enzimler, yapısal ve ekstraselüler faktörler gibi özelliklerle ilişkilidir. Konakçı hücre dışı matriks bileşenlerine yapışmayı sağlamak, konakçı hücrelere zarar vermek ve bağışıklık sistemini güçlendirmek için salgılanan ve hücre yüzeyiyle ilişkili virülens faktörleri enfeksiyonun gelişimine katkı sağlamaktadır. Etkenin dokulara yapışmasını sağlayan en az 25 farklı toksin, adezin matriks molekülleri ile ilişkisi olan 15 mikrobiyal yüzey bileşeni, 20 immunsüpresif molekül ve diğer birçok virülens faktörü bilinmektedir (Fursovave ark., 2020).

S. aureus izolatlarının moleküler karakterizasyonunda koagülaz geni (coa), metisilin direnç geni (femA) ve termonükleaz geni (nuc) gibi tür spesifik genler kullanılmaktadır. Hem coa hem de femA yüksek polimorfizm gösterir ve teşhis amaçları için uygun değildir. Aksine nuc, hem insan hem de hayvan izolatlarında türe özgü bir markör olarak sıklıkla kullanılmaktadır. Ayrıca bu gen $S$. aureus suşları arasında yüksek oranda korunmaktadır (Ronco ve ark., 2018).

Bu çalışmada mastitisli sığır sütlerinden elde edilen S. aureus izolatlarının nuc geni yönünden tür düzeyinde moleküler tanımlanması ve mastitisin patogenezinde rol oynayan lökotoksin, stafilokokal klasik enterotoksin, eksfolyatif toksin, hemolizin, adezin faktör, toksik şok sendrom toksini oluşumundan sorumlu $p v l$, sea, seb, sec, eta, etb, $h l a, h l b, f n b A, f n b B, c l f a$ ve tst genlerimPZR ile incelenmesi amaçlandı.

\section{Materyal ve Metot}

Staphylococcus spp. İzolatları: Çalışmanın materyalini Ondokuz Mayıs Üniversitesi Veteriner Fakültesi Mikrobiyoloji Anabilim Dalı Laboratuvarı kültür koleksiyonu içerisinde yer alan, 2016-2020 arasında subklinik mastitisli sığırlardan izole edilmiş 140 stafilokok izolatı kullanıldı. Çalışma kapsamında kültür koleksiyonunda yer alan izolatlar kullanılması sebebiyle örnek toplama ve saha çalışması yapılmamıştır. Bu nedenle herhangi bir etik kurul iznine intiyaç duyulmamıştır. İzolatların canlandırılması \%5 Koyun kanlı agar kullanılarak yapıldı ardından DNA ekstrasiyonunun yapılması için üreyen saf koloniler TSA'da pasajlandı.
Moleküler İdentifikasyon

DNA Ekstraksiyonu: İzolatlardan bakteriyel DNA ekstraksiyonu için kaynatma yöntemi kullanıldı (Vurucu ve ark., 2019). Bu amaçla, saf kültürden 4 koloni seçilerek $200 \mu \mathrm{l}$ steril su içerisinde süspanse edildi. Örnekleri içeren süspansiyonlar $100^{\circ} \mathrm{C}^{\prime}$ de 15 dakika kaynatıldı, 10.000 g'de 10 dakika santrifüj sonrası elde edilen süpernatant kalıp DNA olarak kullanılmak üzere nanodrop spektrofotometre ile ölçülerek $50 \mathrm{ng} / \mu \mathrm{l}$ olacak şekilde ayarlanarak $20^{\circ} \mathrm{C}^{\prime}$ de saklandı.

S. aureus İzolatlarının Tür Düzeyinde İdentifikasyonu: İzolatların S. aureus olarak identifikasyonlarının doğrulanması amacıyla $S$. aureus spesifik nuc geni için PZR yapıldı (Sezener ve ark., 2019). Bu amaçla $25 \mu l^{\prime} l i k$ bir PZR karışımı, DEPC-treatedwater, $1 \mathrm{X}$ PZR solüsyonu, $2.5 \mathrm{mM}$ $\mathrm{MgCl}_{2}, 0.2 \mathrm{mM}$ her bir dNTP, $1.0 \mathrm{U}$ Taq DNA polimeraz, $0.04 \mu \mathrm{M}$ primer (nuc 1, GCG ATT GAT GGT GAT ACG GTT; nuc 2, AGC CAA GCC TTG ACG AAC TAA AGC) ve $5 \mu$ template DNA kullanıldı. PZR karışımları $94^{\circ} \mathrm{C}^{\prime}$ de $5 \mathrm{dk}$ ön denatürasyonu takiben $94^{\circ} \mathrm{C}^{\prime}$ de $1 \mathrm{dk}$ denatürasyon, $58^{\circ} \mathrm{C}^{\prime}$ de 30 saniye primer bağlanma, $72^{\circ} \mathrm{C}^{\prime}$ de $90 \mathrm{dk}$ uzama olmak üzere 35 siklus ve $72^{\circ} \mathrm{C}^{\prime} \mathrm{de} 10 \mathrm{dk}$ son uzama koşullarında amplifikasyon işlemine tabi tutuldu. Amplifikasyon ürünleri etidium bromid $(2 \mu \mathrm{g} / \mathrm{ml})$ içeren $\% 1,5^{\prime}$ lik agaroz jel elektroforezi sonrasında UV transilluminatör (Vilber Lourmat) ile görüntülendi. Görüntüleme sonrasında nuc geni için 279 bp'lik bir bandın görülmesi $S$. aureus'un göstergesi olarak kabul edildi.

S. aureus İzolatlarının Virülens Genlerinin Belirlenmesi: İzolatlarda, mastitisin patogenezisinde rol oynayan bazı önemli virülens genlerinin belirlenmesi amaciyla multiplex PZR (mPZR) çalışmaları yapıldı. Lökotoksin geni $(p v l)$, stafilokokal klasik enterotoksin genleri (sea, seb, sec), eksfolyatif toksin genleri (eta, etb), hemolizin genleri $(h l a, h l b)$, adezin faktör genleri $(f n b A, f n b B, c l f a)$ ve toksik şok sendrom toksin geni (tst) Tablo 1, Tablo 2 ve Tablo 3'de belirtilen spesifik primerler ve PZR koşulları kullanılarak incelendi. mPZR çalışmaları Li ve ark. (2018)'nin bildirdiği metodun modifikasyonu ile gerçekleştirildi. PZR koşulları: $94^{\circ} \mathrm{C}^{\prime}$ de 5 dakika ilk denatürasyon, $94^{\circ} \mathrm{C}^{\prime}$ de 30 saniye denatürasyon, her gen için spesifik primer bağlanma (annealing) Isısında $\left(55-56^{\circ} \mathrm{C}\right) 45$ saniye, $72^{\circ} \mathrm{C}^{\prime}$ de benzer şekilde spesifik uzama zamanında 30 siklus, son uzama $72^{\circ} \mathrm{C}^{\prime}$ de 10 dakika olacak şekilde gerçekleştirildi. Amplifikasyon ürünleri etidiumbromid $(2 \mu \mathrm{g} / \mathrm{ml})$ içeren \%1.5'lik agaroz jel elektroforezi sonrasında UV transilluminatör ile görüntülendi. PZR çalışmalarında pozitif kontrol olarak S. auerus ATCC 23235, negatif kontrol olarak E. coli ATCC 25922 kullanıldı. 
Tablo 1. pvl, etb, sea ve clfa genleri için MPZR 1.

\begin{tabular}{|c|c|c|c|c|c|}
\hline Gen & Primer & Nükleotid sekans (5'-3') & $\begin{array}{l}\text { Ürün } \\
\text { (bp) }\end{array}$ & $\begin{array}{c}\text { Annealing } \\
\text { ISISI }\end{array}$ & Miktar( $\mu l)$ \\
\hline \multirow{2}{*}{$p v l$} & PVL-F & ATCATTAGGTAAAATGTCTGGACATGATCCA & \multirow{2}{*}{433} & & \multirow{2}{*}{0.2} \\
\hline & PVL-R & GCATCAASTGTATTGGATAGCAAAAGC & & & \\
\hline \multirow{2}{*}{$e t b$} & ETB-F & CAGATAAAGAGCTTTATACACACATTAC & \multirow{2}{*}{612} & & \multirow{2}{*}{0.2} \\
\hline & ETB-R & AGTGAACTTATCTTTCTATTGAAAAACACTC & & & \\
\hline \multirow{2}{*}{ sea } & SEA-F & GAAAAAAGTCTGAATTGCAGGGAACA & \multirow{2}{*}{560} & $55^{\circ} \mathrm{C}$ & \multirow{2}{*}{0.4} \\
\hline & SEA-R & CAAATAAATCGTAATTAACCGAAGGTTC & & & \\
\hline \multirow{6}{*}{ clfa } & CLFA-F & ATTGGCGTGGCTTCAGTGCT & \multirow{2}{*}{\multicolumn{2}{|c|}{292}} & \multirow{2}{*}{0.1} \\
\hline & CLFA-R & CGTTTCTTCCGTAGTTGCATTTG & & & \\
\hline & & & & Master mix & 12.5 \\
\hline & & & \multicolumn{2}{|c|}{ Steril distile su } & 8.7 \\
\hline & & & \multicolumn{2}{|c|}{ Template DNA } & 2 \\
\hline & & & \multicolumn{2}{|c|}{ Toplam hacim } & 25 \\
\hline
\end{tabular}

Tablo 2.sec, tst, seb ve etagenleri için MPZR 2.

\begin{tabular}{|c|c|c|c|c|c|}
\hline Gen & Primer & Nükleotid sekans $\left(5^{\prime}-3^{\prime}\right)$ & $\begin{array}{l}\text { Ürün } \\
\text { (bp) }\end{array}$ & $\begin{array}{c}\text { Annealing } \\
\text { ISISI }\end{array}$ & Miktar( $\mu l)$ \\
\hline \multirow{2}{*}{$\sec$} & SEC-F & GTAAAGTTACAGGTGGCAAAACTTG & \multirow{2}{*}{297} & & \multirow{2}{*}{1} \\
\hline & SEC-R & CATATCATACCAAAAAGTATTGCCGT & & & \\
\hline \multirow{2}{*}{ tst } & TST-F & TTCACTATTTGTAAAAGTGTCAGACCCACT & \multirow{2}{*}{180} & & \multirow{2}{*}{1} \\
\hline & TST-R & TACTAATGAATTTTTTTTATCGTAAGCCCTT & & & \\
\hline \multirow{2}{*}{ seb } & SEB-F & ATTCTATTAAGGACACTAAGTTAGGGA & \multirow{2}{*}{404} & $56^{\circ} \mathrm{C}$ & \multirow{2}{*}{0.2} \\
\hline & SEB-R & ATCCCGTTTCATAAGGCGAGT & & & \\
\hline \multirow{6}{*}{ eta } & ETA-F & CGCTGCGGACATTCCTACATGG & \multirow{2}{*}{676} & & \multirow{2}{*}{0.4} \\
\hline & ETA-R & TACATGCCCGCCACTTGCTTGT & & & \\
\hline & & & & Master mix & 25 \\
\hline & & & \multicolumn{2}{|c|}{ Steril distile su } & 17.8 \\
\hline & & & \multicolumn{2}{|c|}{ Template DNA } & 2 \\
\hline & & & \multicolumn{2}{|c|}{ Toplam hacim } & 50 \\
\hline
\end{tabular}

Tablo 3. $f n b B, f n b A$, hla ve $h l b$ genleri için $\mathrm{mPZR} 3$.

\begin{tabular}{|c|c|c|c|c|c|}
\hline Gen & Primer & Nükleotid sekans (5'-3') & $\begin{array}{l}\text { Ürün } \\
\text { (bp) }\end{array}$ & $\begin{array}{c}\text { Annealing } \\
\text { ISISI }\end{array}$ & Miktar( $\mu \mathrm{l})$ \\
\hline \multirow{2}{*}{$f n b A$} & FNBA-F & GTGAAGTTTTAGAAGGTGGAAAGATTAG & \multirow{2}{*}{643} & & \multirow{2}{*}{0.4} \\
\hline & FNBA-R & GCTCTTGTAAGACCATTTTTTCTTCAC & & & \\
\hline \multirow{2}{*}{$f n b B$} & FNBB-F & GTAACAGCTAATGGTCGAATTGATACT & \multirow{2}{*}{524} & & \multirow{2}{*}{0.4} \\
\hline & FNBB-R & CAAGTTCGATAGGAGTACTATGTTC & & & \\
\hline \multirow{2}{*}{ hla } & HLA-F & CTGATTACTATCCAAGAAATTCGATTG & \multirow{2}{*}{209} & $56^{\circ} \mathrm{C}$ & \multirow{2}{*}{0.4} \\
\hline & HLA-R & CTTTCCAGCCTACTTTTTTATACAGT & & & \\
\hline \multirow{6}{*}{$h / b$} & HLB-F & GTGCACTTACTGACAATAGTGC & \multirow{2}{*}{309} & & \multirow{2}{*}{0.4} \\
\hline & HLB-R & GTTGATGAGTAGCTACCTTCAGT & & & \\
\hline & & & & Master mix & 12.5 \\
\hline & & & \multicolumn{2}{|c|}{ Steril distile su } & 7.3 \\
\hline & & & \multicolumn{2}{|c|}{ Template DNA } & 2 \\
\hline & & & \multicolumn{2}{|c|}{ Toplam hacim } & 25 \\
\hline
\end{tabular}


Tablo 4. S. aureus izolatlarında belirlenen virülens genlerin dağılımı.

\begin{tabular}{|c|c|c|c|c|c|c|c|c|c|c|c|c|}
\hline \multirow[b]{2}{*}{ İzolat no } & \multicolumn{12}{|c|}{ Virülens Genleri } \\
\hline & clfa & hla & $h / b$ & $f n b B$ & $f n b A$ & $e t b$ & $\mathrm{sec}$ & tst & sea & $p v l$ & eta & $s e b$ \\
\hline 1 & + & + & + & + & - & - & - & - & - & - & - & - \\
\hline 2 & + & + & + & + & - & - & - & - & - & - & - & - \\
\hline 3 & + & - & - & - & - & - & - & - & - & - & - & - \\
\hline 4 & + & - & - & - & - & - & - & - & - & - & - & - \\
\hline 5 & + & - & - & - & - & - & - & - & - & - & + & - \\
\hline 6 & - & - & - & - & - & - & + & - & - & - & - & - \\
\hline 7 & + & - & - & - & + & + & - & - & - & - & - & - \\
\hline 8 & + & + & - & - & - & - & - & - & - & - & - & - \\
\hline 9 & + & + & - & + & - & - & - & - & - & - & - & - \\
\hline 10 & + & + & - & + & - & - & - & - & - & - & - & - \\
\hline 11 & + & + & - & - & - & - & - & + & - & - & - & - \\
\hline 12 & + & + & - & - & + & - & - & - & - & - & - & - \\
\hline 13 & + & + & - & - & + & - & - & - & - & - & - & - \\
\hline 14 & + & + & + & + & - & - & - & - & - & - & - & - \\
\hline 15 & - & - & - & - & - & - & - & - & - & - & - & - \\
\hline 16 & - & - & - & - & - & - & - & - & - & - & - & - \\
\hline 17 & - & - & - & - & - & - & + & - & - & - & - & - \\
\hline 18 & + & + & - & - & - & - & - & + & - & - & - & - \\
\hline 19 & - & - & - & - & - & - & - & + & - & - & - & - \\
\hline 20 & + & + & + & + & - & + & - & + & - & - & - & - \\
\hline 21 & - & - & - & - & - & - & - & + & - & - & - & - \\
\hline 22 & + & + & + & - & + & - & - & - & + & - & - & - \\
\hline 23 & - & - & - & - & - & - & + & - & - & - & - & - \\
\hline 24 & - & - & - & - & + & + & - & - & - & - & - & - \\
\hline 25 & - & - & - & - & - & - & - & - & - & - & - & - \\
\hline 26 & + & - & - & - & - & + & + & - & - & - & - & - \\
\hline 27 & + & + & + & + & + & - & - & - & - & - & - & - \\
\hline 28 & + & + & + & + & - & - & - & - & - & - & - & - \\
\hline 29 & - & - & - & - & - & + & + & - & - & - & - & - \\
\hline 30 & - & - & - & - & - & - & - & - & - & - & - & - \\
\hline 31 & - & - & - & - & - & + & - & - & - & - & - & - \\
\hline 32 & + & + & + & + & - & - & - & - & - & - & - & - \\
\hline 33 & + & + & + & + & - & - & - & - & - & - & - & - \\
\hline 34 & + & + & + & - & - & - & - & - & - & - & - & - \\
\hline 35 & + & + & + & - & - & - & - & - & - & - & - & - \\
\hline 36 & + & + & + & - & - & - & - & - & - & + & - & - \\
\hline 37 & + & - & - & - & - & - & - & - & - & - & - & - \\
\hline 38 & + & + & + & - & - & - & - & - & + & - & - & - \\
\hline 39 & + & + & + & - & - & - & - & - & + & - & - & - \\
\hline 40 & + & + & - & - & - & - & - & - & - & - & - & - \\
\hline 41 & + & + & - & - & - & - & - & - & - & + & - & - \\
\hline 42 & + & + & - & - & - & - & - & - & - & - & - & - \\
\hline Toplam & 30 & 24 & 14 & 10 & 6 & 6 & 5 & 5 & 3 & 2 & 1 & 0 \\
\hline$\%$ & 71.4 & 57.1 & 33.3 & 23.8 & 14.2 & 14.2 & 11.9 & 11.9 & 7.1 & 4.7 & 2.3 & 0 \\
\hline
\end{tabular}


Tablo 5. S. aureus izolatlarında belirlenen çoğul virülens gen profili.

\begin{tabular}{|c|c|}
\hline Çoğul Virülens Genler & İzolat sayısı \\
\hline$c l f a+h l a+h l b+f n b B+e t b+t s t$ & 1 \\
\hline$c l f a+h l a+h l b+f n b B+f n b A$ & 1 \\
\hline$c l f a+h l a+h l b+f n b A+s e a$ & 1 \\
\hline$c l f a+h l a+h l b+f n b B$ & 6 \\
\hline$c l f a+h l a+h l b+p v l$ & 1 \\
\hline$c l f a+h l a+h l b+s e a$ & 2 \\
\hline$c l f a+f n b A+e t b$ & 1 \\
\hline$c l f a+h l a+f n b B$ & 2 \\
\hline$c l f a+h l a+t s t$ & 2 \\
\hline$c l f a+h l a+f n b A$ & 2 \\
\hline$c l f a+e t b+s e c$ & 1 \\
\hline$c l f a+h l a+h l b$ & 2 \\
\hline$c l f a+h l a+p v l$ & 1 \\
\hline clfa+eta & 1 \\
\hline$c / f a+h l a$ & 3 \\
\hline$f n b A+e t b$ & 1 \\
\hline$e t b+s e c$ & 1 \\
\hline Toplam & 29 \\
\hline
\end{tabular}

\section{Bulgular}

\section{S. aureus İzolatlarında nuc Geni Hedefli PZR}

Sonuçları: Mevcut $S$. aureus izolatlarının genotipik identifikasyonunun belirlenmesi için toplam 140 stafilokok izolatının termonükleaz (nuc) geni varlığı $P Z R$ ile incelendi. nuc genine spesifik primerle yapılan PZR sonrasında, 42 izolatta 279 bp'lik PZR ürünü elde edilip izolatların $S$. aureus oldukları belirlendi (Şekil 1).

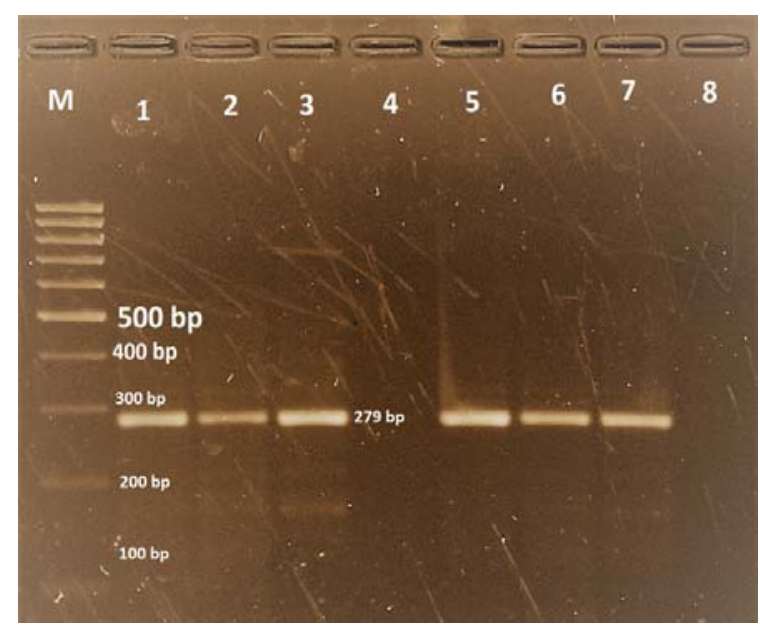

Şekil 1. S. aureus izolatlarının nuc geni spesifik PZR ürünü. $M$ : Moleküler ağırık marker (Gene Ruler 100 bp DNA Ladder Plus, Fermentas, Litvanya). 1,2,3,5,6: nuc geni pozitif (279 bp) örnekler. 4: Negatif örnek. 7: Pozitif kontrol (S. aureus 23235) 8: Negatif kontrol (E. coli ATCC 25922).

S. aureus İzolatlarında Virülens Gen Profili: $\mathrm{Bu}$ çalışmada nuc geni ile $S$. aureus oldukları doğrulanmış 42 izolatın lökotoksin geni (pvl), stafilokokal klasik enterotoksin genleri (sea, seb, $s e c)$, eksfolyatif toksin genleri (eta, etb), hemolizin genleri $(h l a, h / b)$, adezin faktör genleri $(f n b A, f n b B$, clfa) ve toksik şok sendrom toksin geni (tst) varlığı 3 farklı mPZR ile incelendi. pvl, etb, sea ve clfa genlerine ait MPZR 1 sonuçları Şekil 2, sec, tst, seb ve eta genleri için mPZR 2 sonuçları Şekil 3 ve $f n b B$, $f n b A$, hla ve $h l b$ genleri için mPZR 3 sonuçları Şekil 4 'de gösterildi.

İzolatların $30 \quad(\% 71,4)^{\prime}$ unda $\quad$ clfa, 24 $(\% 57,1)^{\prime}$ ünde $h / a, 14 \quad(\% 33,3)^{\prime}$ ünde $h / b, 10$ (\%23,8)'unda fnbB, 6 (\%14,2)'sında fnbA, 6 (\%14,2)'sında etb, 5 (\%11,9)'inde sec, 5 (\%11,9)'inde tst, $3(\% 7,1)$ 'ünde sea, $2(\% 4,7)$ 'sinde $p v l$ ve 1 $(\% 2,3)$ 'inde eta geni tespit edildi. İzolatların hiçbirinde seb geni saptanamadı (Tablo 4, Şekil 5). İzolatların 29'unda, 17 farklı virülens gen profilinden oluşan, iki ya da daha fazla virülens gene çoğul pozitiflik belirlendi (Tablo 5).

\section{Tartışma ve Sonuç}

S. aureus nedenli mastitis oluşumu farklı patogenez mekanizmalarına sahip enterotoksinler, hemolizinler, clumping faktör, fibrinolektin bağlayan proteinler gibi çeşitli virülens faktörlerin üretimine bağlıdır (Boynukara ve ark., 2008). S. aureus suşlarının patojenisitesindeki farklılıklar coğrafi dağılımdan, konakçı ve doku ile ilgili özelliklerden kaynaklanmaktadır. Virülens genlerinin sayısı ve kombinasyonu, $S$. aureus suşlarının patojenik potansiyeline önemli katkılar sağlamaktadır (Kot ve ark., 2016). 


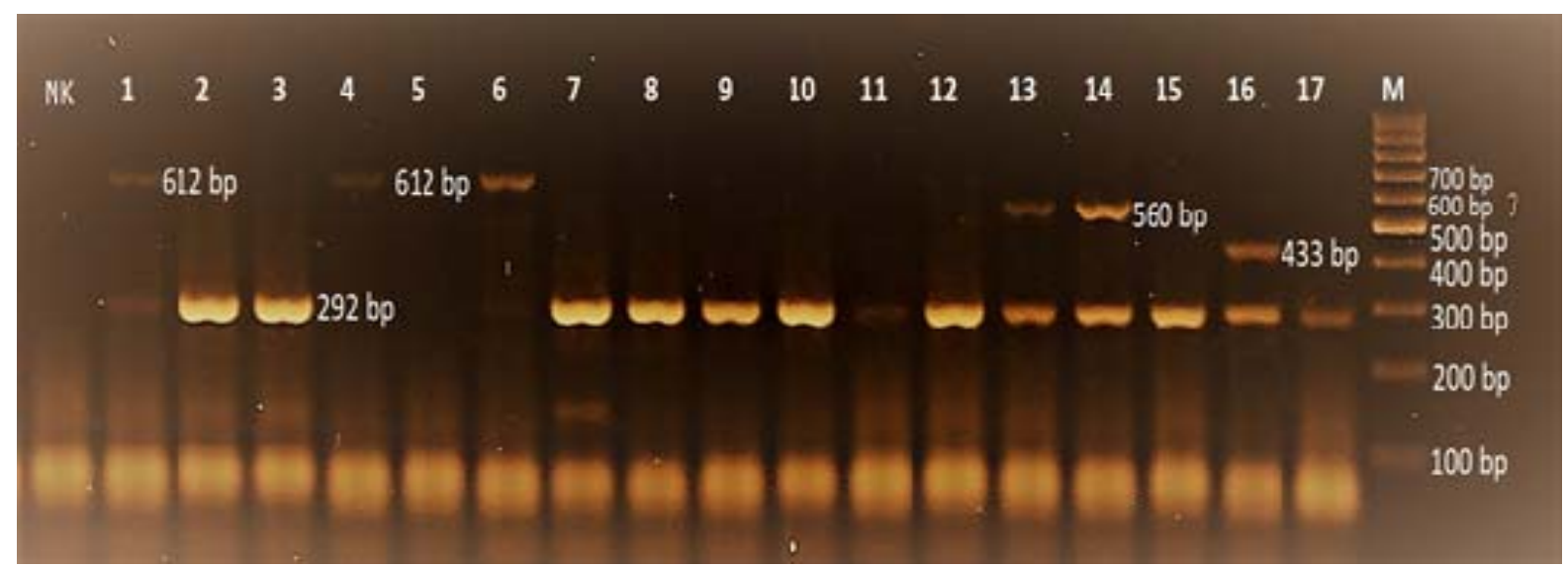

Şekil 2. $p v l$, etb, sea ve $c$ lfa genlerine ait mPZR 1 sonuçları. M: Moleküler ağırlık marker (Gene Ruler 100 bp DNA Ladder Plus, Fermentas, Litvanya). NK: Negatif kontrol (DNase-RNasefree PZR suyu); 1: clfa ve etb genleri (292 bp ve 612 bp) pozitif örnekler; 2,3,7,8,9,10,11,12,15,17: clfa geni (292 bp) pozitif örnekler; 4 ve 6: etb geni (612 bp) pozitif örnekler; 5: tüm genler ( $p v l$, etb, sea ve clfa) açısından negatif örnek; 13 ve 14:clfa ve sea genleri (292 bp ve 560 bp) pozitif örnekler; 16: clfa ve pvl genleri (292 bp ve 433 bp) pozitif örnek.

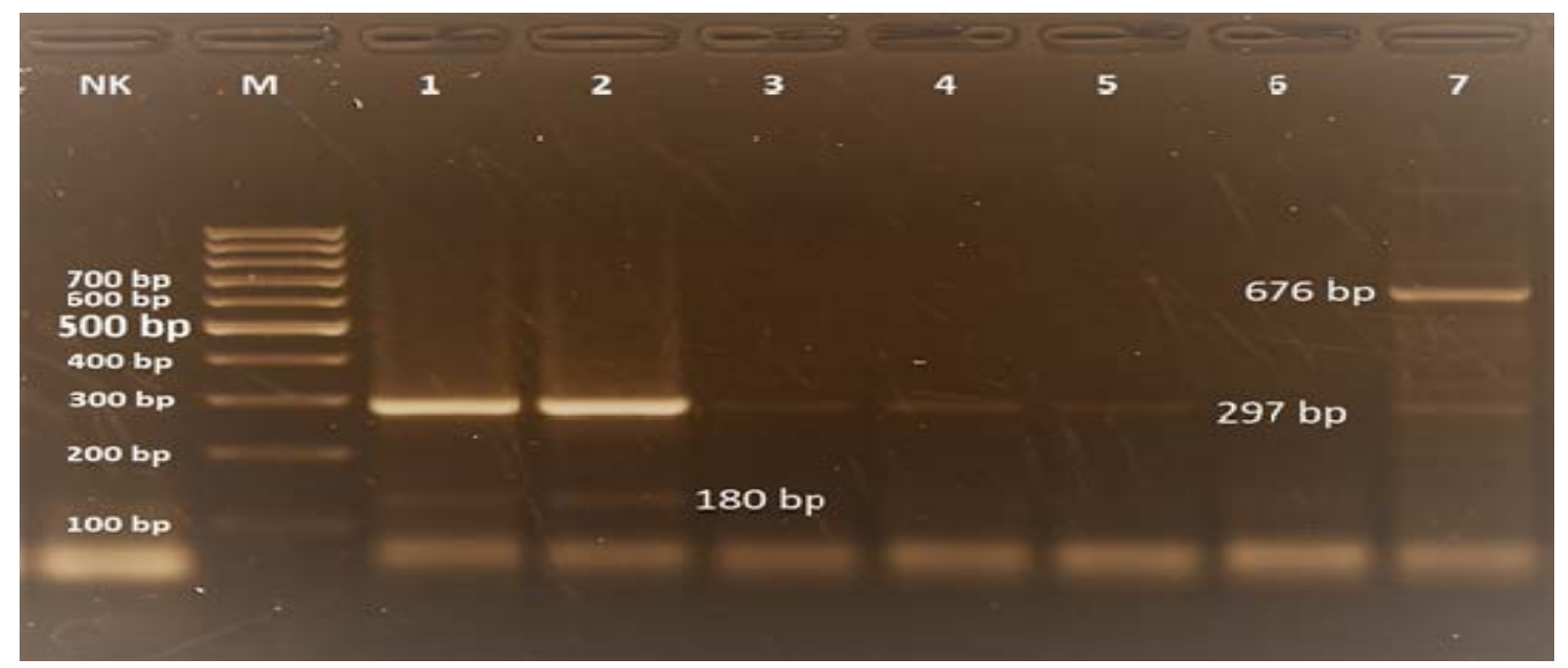

Şekil 3. sec, tst, seb ve eta genleri için mPZR 2 sonuçları. M: Moleküler ağılık marker (Gene Ruler 100 bp DNA Ladder Plus, Fermentas, Litvanya). NK: Negatif kontrol (DNase-RNasefree PZR suyu); 1,2: sec ve tst genleri (297 bp ve 180 bp) pozitif örnekler; 3,4,5: sec geni (297 bp) pozitif örnek; 7: eta geni (676 bp) pozitif örnek; 6; tüm genler (sec, tst, seb ve eta) açısından negatif örnek.

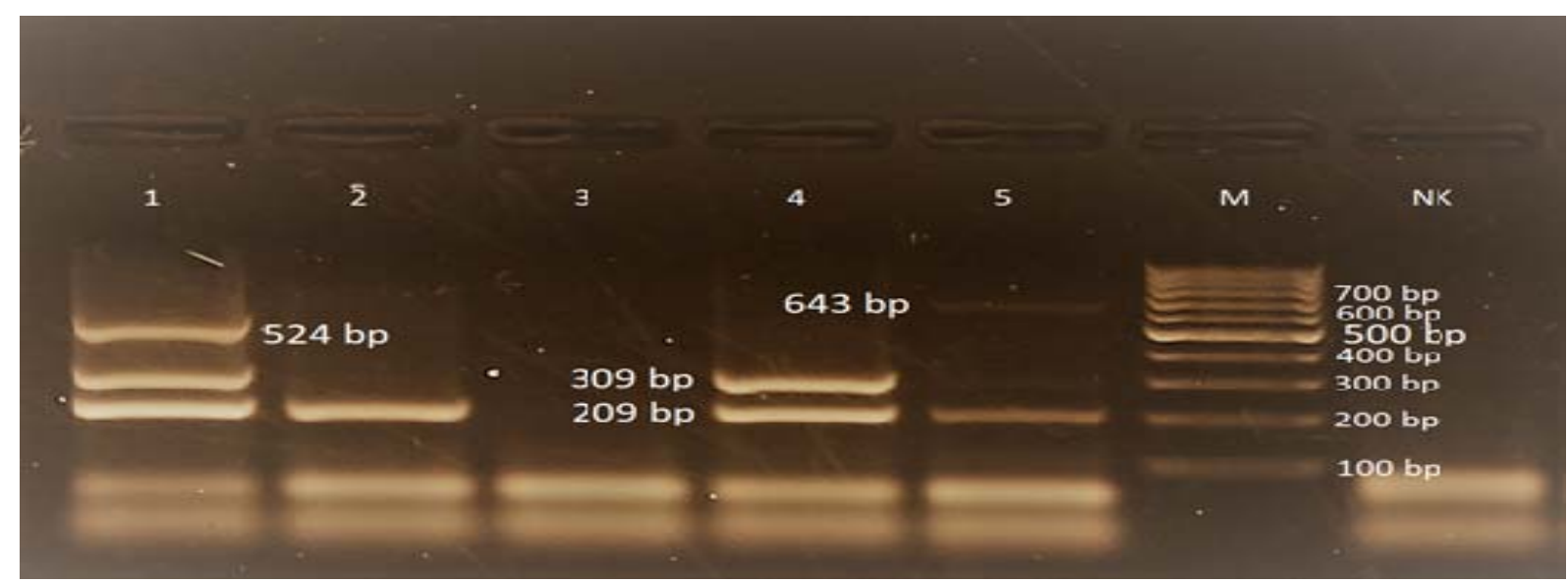

Şekil 4. $f n b B, f n b A$, hla ve $h l b$ genleri için mPZR 3 sonuçları. M: Moleküler ağılık marker (Gene Ruler 100 bp DNA Ladder Plus, Fermentas, Litvanya). NK: Negatif kontrol (DNase-RNase free PZR suyu); 1: hla (209 bp), hlb (309 bp) ve fnbB (524 bp) genleri pozitif örnek; 2: hla (209 bp) pozitif örnek; 3: tüm genler (fnbB, fnbA, hla ve $h l b$ ) açısından negatif örnek; 4: hla (209 bp) ve hlb (309 bp) genleri pozitif örnek; 5: hla (209 bp) ve $f n b A(643 \mathrm{bp})$ genleri pozitif örnek. 


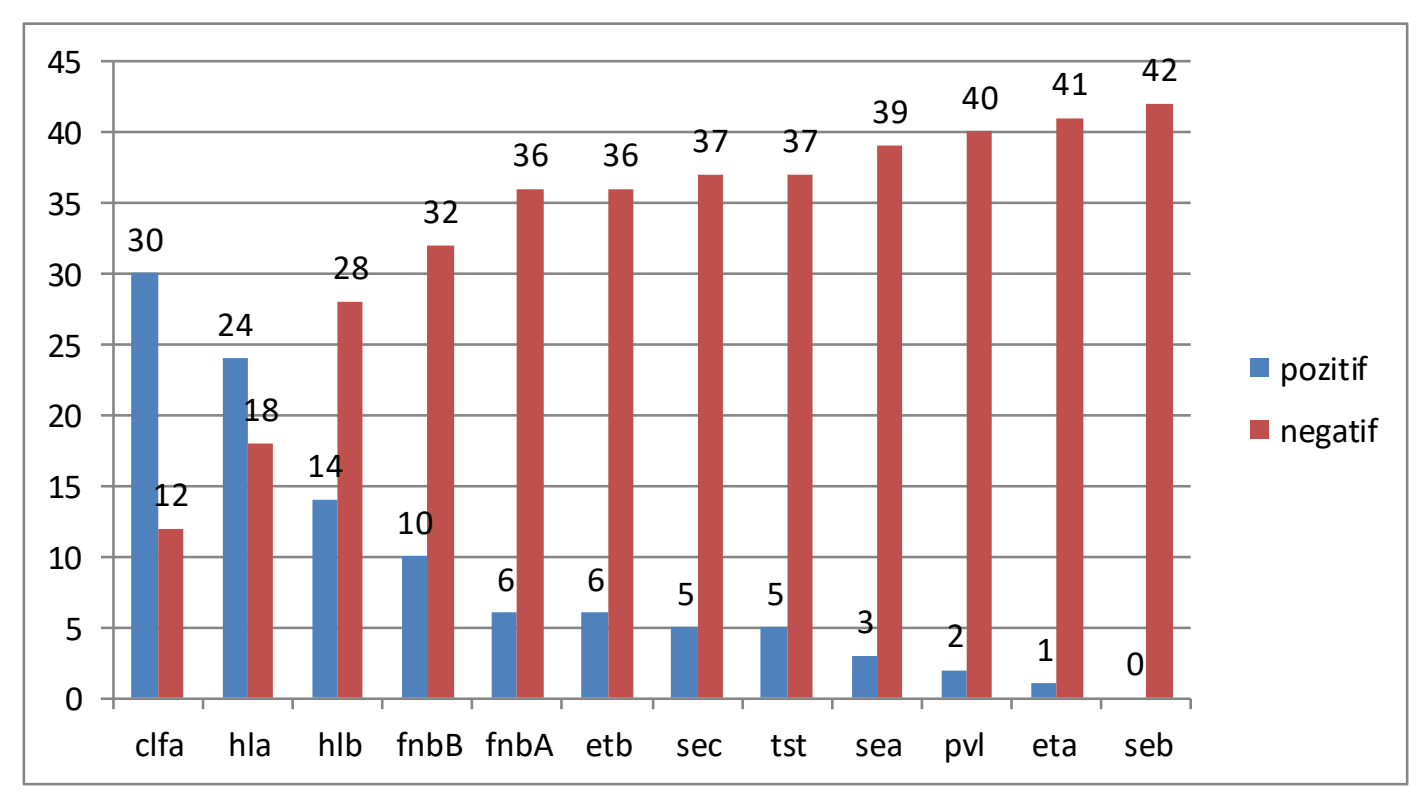

Şekil 5. S. aureus izolatlarında belirlenen virülens genlerin dağılımı.

Sığır mastitislerinin etiyolojisinde önemli yer tutan S. aureus'un virülens genlerinin ortaya konulması ve patogenezde önemli rol oynayan faktörlerin karakterizasyonu amacıyla çok sayıda araştırma yapılmıştır.

$\mathrm{Bu}$ çalışmalarda incelenen $S$. aureus izolatlarında sıklıkla belirlenen virülens genlerinin clfa (Fursova ve ark., 2020; Ote ve ark., 2011; Xu ve ark., 2015; Yang ve ark., 2020; Zhang ve ark., 2018 ), hla (Artursson ve ark., 2016; Fursova ve ark., 2018; Kreausukon ve ark., 2012; Ronco ve ark., 2018; Wang ve ark., 2016 ), sea (Grispoldi ve ark., 2019; Liu ve ark., 2017; Seyoum ve ark., 2016 ), fnbA (Pereyra ve ark., 2016; Yang ve ark., 2012; Zuniga ve ark., 2015), fnbB (Bar-Gal ve ark., 2015; Kot ve ark., 2016), pvl (Wang ve ark., 2014) tst (Wang ve ark., 2017) sec (Kotzamanidis ve ark., 2021) olduğu bildirilmiştir. Araştırmalarda S. aureus kökenli sığır mastitislerinin patogenezinde bu genlerin önemli rol oynadığına dikkat çekilmiştir.

Konuyla ilgili farklı ülkelerde sığır mastitis vakalarından izole edilen S.aureus izolatlarında virülens genlerin tespitine yönelik yapılan çalışmalarda patogenezde rol oynayan faktörlerin çok değişken olduğu ortaya konulmuştur. Bazı çalışmalarda primer olarak belirlenen genlerin clfa ve hla olduğu görülmektedir. Bu çalışmada incelenen $S$. aureus izolatlarında belirlenen en önemli virülens genlerinin clfa ve hla olması literatür verileriyle paralellik göstermektedir (Coelho ve ark., 2011; Fitzgerald ve ark., 2000; Monecke ve ark., 2007; Oteve ark., 2011). Araştırma verileri arasındaki farklılıklar bölgesel, metodik, izolat sayısı ve çeşitliliği, popülasyon yapısı gibi birçok faktöre bağlı şekillenebilmektedir. Diğer yandan pek çok araştırma verilerinde sunulduğu gibi, sığır mastitislerinin oluşumuna katılan S. aureus izolatlarının farklı virotiplere sahip olduğu tespit edilmiştir. $\mathrm{Bu}$ nedenle sığır mastitislerinin etiyolojisini detaylı bir şekilde ortaya koymak için, daha kapsamlı epidemiyolojik çalışmalara ihtiyaç duyulmaktadır. Böylece sığır mastitislerin önlenmesinde koruyucu aşılama programları ve daha kapsamlı aşı içeriklerinin hazırlanması mümkün olabilecektir.

Bu çalışmada sığır mastitislerinden izole edilen ve nuc geni pozitif $42 \mathrm{~S}$. aureus izolatı 12 farklı virülens geni açısından $\mathrm{mPZR}$ ile incelendi. $42 \mathrm{~S}$. aureus izolatının $38^{\prime}$ inde bir ya da daha fazla virülens geni belirlenirken, 4 izolatta incelenen virülens genlerin hiçbiri saptanamadı. Incelenen izolatlarda en fazla tespit edilen virülens genlerin clfa ve hla olduğu görüldü. İzolatların 29'unda iki ya da daha fazla virülens gen açısından çoğul pozitiflik belirlendi. Çoğul pozitiflik belirlenen izolatların 6 'sının 4 gen $(c l f a+h l a+h l b+f n b B)$ açısından birlikte pozitif olduğu görüldü. Diğer yandan bir izolatta 6

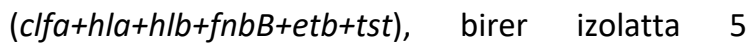
$(c l f a+h l a+h l b+f n b B+f n b A$ ve $c l f a+h l a+h l b+f n b A+s e a)$ farklı virülens genin birlikte var olduğu tespit edildi. Araştırılan virülens genleri açısından negatif bulunan izolatlarda mastitis oluşumundan sorumlu başka virülens faktörlerinin var olabileceği düşünüldü.

Sonuç olarak bu çalışma ile sınırlı dahi olsa sığır mastitislerinin patogenezisinde rol oynayan virülens gen paternleri ortaya konuldu. Çalışma sonuçlarının sığır mastitislerinin etiyolojisinde önemli rol oynayan S. aureus'a ait virülens faktörlerinin karakterizasyonu çalışmalarına katkı sağlayacağı kanaatine varıldı. Sığır mastitislerinin önlenmesine yönelik hazırlanacak aşı kompozisyonunun 
şekillendirilmesinde $S$. aureus virülens gen çeşitliliğinin bilinmesi önem arz etmektedir. Bu nedenle kullanılacak aşının çok sayıda virülens faktörüne sahip suşlardan oluşturulması gerekmektedir. Bu çalışmada incelenen $S$. aureus izolatlarının çoğunun farklı virülens gen profiline sahip olması, izolatların aşı suşu olarak kullanılabilecek potansiyelde olduğunu göstermektedir. Ancak izolatların aşı suşu potansiyelinin tam olarak ortaya konulması için ileri seviyede karakterizasyon çalışmaları yapılmalıdır. Sığır mastitislerinden izole edilen $S$. aureus izolatlarının mastitis patogenezisinde rol oynayan virülens gen çeşitliliğinin ortaya konulması amacıyla daha fazla izolat içeren epidemiyolojik çalışmalara ihtiyaç duyulmaktadır.

\section{Teşekkür}

$\mathrm{Bu}$ çalışma, Ondokuz Mayıs Üniversitesi Bilimsel Araştırma Projeleri Başkanlığı tarafından PYO.VET.1904.20.015 nolu proje kapsamında maddi olarak desteklenmiş ve aynı isimli yüksek lisans tezinden özetlenmiştir.

\section{Kaynaklar}

Artursson K, Söderlund R, Liu L, Monecke S, Schelin J, 2016: Genotyping of Staphylococcus aureus in bovine mastitis and correlation to phenotypic characteristics. Vet Microbiol, 193, 156-161.

Bar-Gal GK, Blum SE, Hadas L, Ehricht R, Monecke S, Leitner G, 2015: Host-specificity of Staphylococcus aureus causing intramammary infections in dairy animals assessed by genotyping and virulence genes. Vet Microbiol, 176,143-154.

Boynukara B, Gulhan T, Alisarli M, Gurturk K, Solmaz H, 2008: Classical enterotoxigenic characteristics of Staphylococcus aureus strains isolated from bovine subclinical mastitis in Van, Turkey. Int J Food Microbiol, 125(2), 209-211.

Coelho SMO, Pereira IA, Soares LC, Pribul BR, Souza MMS, 2011: Short communication: Profile of virulence factors of Staphylococcusaureus isolated from subclinical bovine mastitis in the state of Rio de Janeiro, Brazil. J Dairy Sci, 94, 3305-3310.

Fitzgerald JR, Hartigan PJ, Meaney WJ, Smyth CJ, 2000: Molecular population and virulence factor analysis of Staphylococcusaureus from bovine intramammary infection. J Appl Microbiol, 88, 10281037.

Fursova KK, Shchannikova MP, Loskutova IV, Shepelyakovskaya AO, Laman AG, Boutanaev AM, Sokolov SL, Artemeva OA, Nikanova DA, Zinovieva NA, Brovko FA, 2018: Exotoxin diversity of Staphylococcus aureus isolated from milk of cows with subclinical mastitis in Central Russia. J Dairy Sci, 101, 4325-4331.
Fursova, K, Sorokin A, Sokolov S, Dzhelyadin T, Shulcheva I, Shchannikova M, Nikanova D, Artemeva O, Zinovieva N, Brovko F, 2020: Virulence factors and phylogeny of Staphylococcus aureus associated with bovine mastitis in Russia based on genome sequences. Front Vet Sci, 7(135), doi: 10.3389/fvets.2020.00135.

Grispoldi L, Massetti L, Sechi P, lulietto MF, Ceccarelli M, Karama M, Popescu PA, Pandolfi F, Cenci-Goga BT, 2019: Short communication: Characterization of enterotoxin-producing Staphylococcus aureus isolated from mastitic cows. J Dairy Sci, 102, 10591065.

Kot B, Szweda P, Frankowska-Maciejewska A, Piechota M, Wolska K, 2016: Virulence gene profiles in Staphylococcus aureus isolated from cows with subclinical mastitis in eastern Poland. J Dair Res, 83, 228-235.

Kotzamanidis C, Vafeas G, Giantzi V, Anastasiadou S, Mygdalias S, Malousi A, Loukia E, Daniel S, Zdragas A, 2021: Staphylococcus aureus isolated from ruminants with mastitis in Northern Greece dairy herds: genetic relatedness and phenotypic and genotypic characterization. Toxins, 13 (3), 176, https://doi.org/10.3390/toxins13030176.

Kreausukon K, Fetsch A, Kraushaar B, Alt K, Müller K, Krömker V, Zessin KH, Käsbohrer A, Tenhagen BA, 2012: Prevalence, antimicrobial resistance, and molecular characterization of methicillin-resistant Staphylococcus aureus from bulk tank milk of dairy herds. J Dairy Sci, 95, 4382-4388.

Li X, Fang F, Zhao J, Lou N, Li C, Huang T, Li Y, 2018: Molecular characteristics and virulence gene profiles of Staphylococcus aureus causing bloodstream infection. Braz J Infect Dis, 22, 487-494.

Liu H, Li S, Meng L, Dong L, Zhao S, Lan X, Wang J, Zheng N, 2017: Prevalence, antimicrobial susceptibility, and molecular characterization of Staphylococcus aureus isolated from dairy herds in northern China. $J$ Dairy Sci, 100, 8796-8803.

Monecke S, Kuhnert $P$, Hotzel $H$, Slickers $P$, Ehricht $R, 2007$ : Microarray based study on virulenceassociated genes and resistance determinants of Staphylococcusaureus isolates from cattle. Vet Microbiol, 125, 128-140.

Ote I, Taminiau B, Duprez JN, Dizier I, Mainil JG, 2011: Genotypic characterization by polymerase chain reaction of Staphylococcus aureus isolates associated with bovine mastitis. Vet Microbiol, 153, 285-292.

Pereyra EAL, Picech F, Renna MS, Baravalle C, Andreotti CS, Russi R, Calvinho LF, Diez C, Dallard BE, 2016: Detection of Staphylococcus aureus adhesion and biofilm-producing genes and their expression during internalization in bovine mammary epithelial cells. Vet Microbiol, 183, 69-77.

Ren Q, Liao G, Wu Z, Lv J, ChenW, 2020: Prevalence and characterization of Staphylococcus aureus isolatesfrom subclinical bovine mastitis in southern Xinjiang, China. J Dairy Sci, 103(4), 3368-3380.

Ronco T, Klaas IC, Stegger M, Svennesen L, Astrup LB, Farre M, Pedersen K, 2018: Genomic investigation of Staphylococcus aureus isolates from bulk tank milk 
and dairy cows with clinical mastitis. Vet Microbiol, 215, 35-42.

Seyoum ET, Mekonene TK, Woldetsadik DA, Zewudie BM, Gebreyes WA, 2016: Enterotoxin gene profile of Staphylococcus aureus isolates recovered from bovine milk produced in central Ethiopia. J Infect Dev Cttries, 10(2), 138-142.

Sezener MG, Fındık A, Ergüden VE, Akgöz $S$, Gülhan $T$, Çiftci A, 2019: Mastitis izolatı Staphylococcus aureus suşlarında antibiyotik dirençliliğinin ve bazı virülens genlerinin araştırılması. J Anatol Environ Animal Sci, 4(2), 182-187.

Vurucu N, Savaşan S, Sezener MG, 2019: Determination of virulence genes and genetic similarities of mastitic milk originated Escherichia coli isolates. East African Scholars J Agri Life Sci, 2(1), 31-35.

Wang D, Zhang L, Zhou X, He Y, Yong C, Shen M, Szenci O, Han B,2016: Antimicrobial susceptibility, virulence genes, and randomly amplified polymorphic DNA analysis of Staphylococcus aureus recovered from bovine mastitis in Ningxia, China. J Dairy Sci, 99, 9560-9569.

Wang D, Zhang L, Yong C, Shen M, Ali T, Shahid M, Han K, Zhou X, Han B, 2017: Relationships among superantigen toxin gene profiles, genotypes, and pathogenic characteristics of Staphylococcus aureus. J Dairy Sci, 100(6), 4276-4286.

Wang $X$, Wang $X$, Wang $Y$, Guo G, Usman T, Hao D, Tang $X$, Zhang $Y, Y u Y, 2014$ : Antimicrobial resistance and toxin gene profiles of Staphylococcus aureus strains from Holstein milk. Lett Appl. Microbiol, 58, 527534.

Xu J, Tan X, Zhang X, Xiaoli X, Sun H, 2015: The diversities of staphylococcal species, virulence and antibiotic resistance genes in the subclinical mastitis milk from a single Chinese cow herd. Microb Pathog, 88, 2938.

Yang FL, Li XS, Liang XW, Zhang XF, Qin GS, Yang BZ, 2012: Detection of virulence associated genes in Staphylococcus aureus isolated from bovine clinical mastitis milk samples in Guangxi. Trop Anim Health Prod, 44, 1821-1826.

Yang $F$, Zhang $S$, Shang $X$, Li H, Zhang $H$, Cui D, Wang $X$, Wang L, Yan Z, Sun Y, 2020: Detection and molecular characterization of methicillin-resistant Staphylococcus aureus isolated from subclinical bovine mastitis cases in China. J Dairy Sci, 103, 840845.

Zhang L, Gao J, Barkema HW, Ali T, Liu G, Deng Y, Naushad S, Kastelic JP, Han B, 2018: Virulence gene profiles: alpha-hemolysin and clonal diversity in Staphylococcus aureus isolates from bovine clinical mastitis in China. Vet Res, 14(63), https://doi.org/10.1186/s12917-018-1374-7.

Zuniga E, Melville PA, Saidenberg ABS, Laes MA, Gonsales FF, Salaberry SRS, Gregori F, Brandao PE, dos Santos FGB, Lincopan NE, Benites NR, 2015: Occurrence of genes coding for MSCRAMM and biofilm-associated protein Bap in Staphylococcus spp. isolated from bovine subclinical mastitis and relationship with somatic cell counts. Microb Pathog, 89, 1-6.

${ }^{*}$ Yazışma Adresi: Timur GÜLHAN

Ondokuz Mayıs Üniversitesi, Veteriner Fakültesi, Mikrobiyoloji Anabilim Dalı, Samsun, Türkiye.

e-mail: timur.gulhan@omu.edu.tr 